\title{
A Comparison of the Abortifacient Risk of Western Juniper Trees in Oregon
}

\author{
By Kevin D. Welch, Daniel Cook, Dale R. Gardner, Cory Parsons, James A. Pfister, \\ and Kip E. Panter
}

\section{On the Ground}

- The bark, leaves, and berries of western juniper trees in Oregon can cause abortions in late-term pregnant cattle.

- The percentage of the abortion-causing compounds varied from tree to tree in a location, as well as between locations across Oregon, but did not appear to vary across time.

- Cattle producers who winter cattle in pastures with western juniper trees should take cautions such as denying late-term pregnant cattle access to these pastures, providing adequate feed and shelter, maintaining pregnant cattle in good body condition, changing calving schedules to late spring or early fall, and, if abortions do occur, seeking veterinary care for any postpartum complications.

Keywords: cattle, abortions, western juniper trees, isocupressic acid, agathic acid, labdane acids.

Rangelands 35(1):40-44

doi: 10.2111/RANGELANDS-D-12-00056.1

(C) 2013 The Society for Range Management

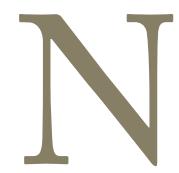

eedles from ponderosa pine (Pinus ponderosa) trees are known to cause late-term abortions in cattle. ${ }^{1}$ Isocupressic acid (ICA), a labdane resin acid in the needles of ponderosa pine, was identified as the abortifacient (abortion-causing) agent. ${ }^{2}$ However, ICA was found to be quickly metabolized in both the rumen and the liver. ${ }^{3}$ The major metabolites of ICA identified thus far include imbricatoloic acid (IMB), agathic acid (AA), dihydroagathic acid (DHAA), and tetrahydroagathic acid (THAA). ${ }^{3,4}$ Additional research has demonstrated that other species of trees also contain ICA and/or metabolites of ICA. ${ }^{5}$ Current management recommendations indicate that any plant material with a concentration greater than $0.5 \%$ ICA (on a dry weight basis), poses a risk for inducing abortions in late-term pregnant cattle, and ICA concentrations over $1 \%$ pose a much higher risk. In addition to ICA, pine trees may also contain IMB, AA, and DHAA. Recently it was reported that the bark of Utah juniper (Juniperus osteosperma), which contains a high concentration of AA ( $1.5 \%$ by dry weight) but no ICA, will induce abortions in cattle, demonstrating that $\mathrm{AA}$ is also an abortifacient in cattle. ${ }^{6}$ Consequently, to date we know ICA and AA are abortifacient compounds; however, it remains uncertain as to whether the other metabolites - IMB, DHAA, or THAA — are biologically active as abortifacient compounds in late-term pregnant cattle.

Recently, there have been several reports of abortion rates of $10-15 \%$ within cattle herds in Oregon after cattle were pastured in areas with abundant western juniper trees $(J u$ niperus occidentalis; personal communications with Oregon ranchers). In each of these instances, there was no ponderosa pine, or other trees previously known to contain ICA, found in these areas, while there was clear visual evidence that cattle had consumed bark and needles from western juniper trees. The losses occurred most often after a significant weather incident, such as high winds that knocked limbs onto the ground or deep snow that covered available grasses, which can result in cattle eating large amounts of juniper bark and needles in a short period of time. Ranchers also reported cattle consuming large amounts of juniper from slash piles or riparian restoration projects using western juniper trees.

Consequently we analyzed the bark, needles, and berries from western juniper trees and determined that western juniper trees contain labdane acids similar to ponderosa pine needles, albeit in lower concentrations. ${ }^{7}$ A follow-up pilot study indicated that the bark from western juniper trees could induce abortions in cattle. ${ }^{7}$ Consequently, western juniper trees appear to be a risk for inducing late-term abortions in cattle. However, this risk is not well characterized and it is unclear how much variation there is in the abortifacient compounds in western juniper trees. A previous report has shown that there can be significant variation in the ICA content of ponderosa pine needles from location to location and over 


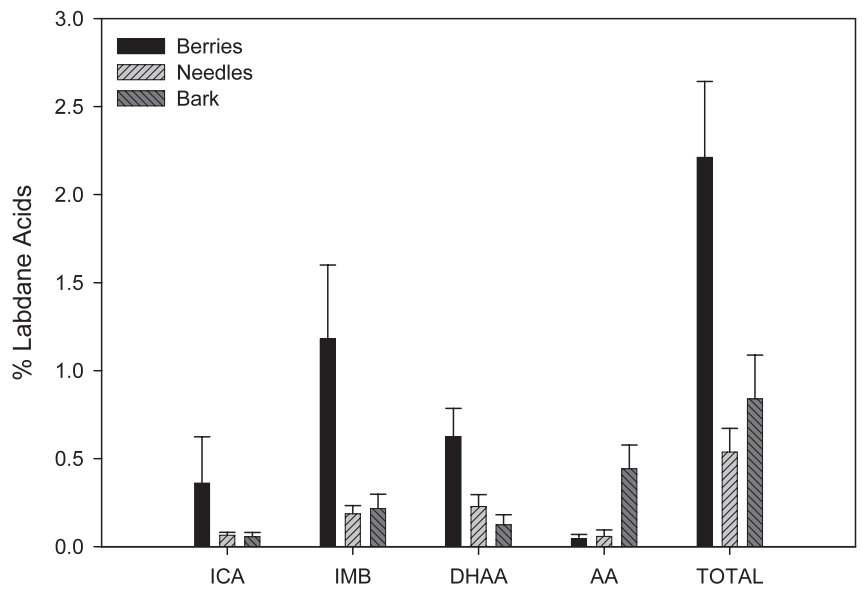

Figure 1. Labdane acid concentrations in bark, needles, and berries from western juniper trees. The labdane acids analyzed were isocupressic acid (ICA), imbricatoloic acid (IMB), dihydroagathic acid (DHAA), agathic acid $(A A)$, and their sum (TOTAL). Data represent the mean \pm SD from eight or nine trees per location from six different locations.

time. ${ }^{8}$ The objective of our study was to collect samples of bark, needles, and berries from western juniper trees across the state of Oregon to determine how much variation there is in the abortion-causing compounds to better understand the variation in potential abortion risk.

\section{Determining Variation in Labdane Acid Concentrations}

Samples of needles, bark, and berries from western juniper trees were collected in January 2011 from six locations (eight or nine trees per location) in Baker County, Oregon, and from 35 locations (10 trees per location) across the state of Oregon in August 2011. Samples were collected from live trees by walking around the tree and randomly taking grab samples of bark, needles, and berries (when present) from a minimum of four sites on the tree from parts of the tree that could be accessed by grazing cattle. The samples were placed into paper bags and allowed to dry at ambient temperature and then analyzed for labdane acid concentrations. The concentration of labdane acids in the plant materials were measured by gas chromatography. ${ }^{9}$ Data are expressed as the mean concentration plus or minus one standard deviation (SD). Statistical comparisons of labdane acid concentrations between multiple samples were made by using a one-way analysis of variance with a Bonferroni post-hoc test. Comparisons between two samples were made using a Student's $t$-test. ${ }^{i}$

\section{Abortion Risk Variability by Location}

The concentration of the labdane acids: ICA, IMB, DHAA, and AA were determined in bark, needles, and berries from eight or nine trees at six different locations in Baker County,

'Differences were considered significant at $P<0.05$.

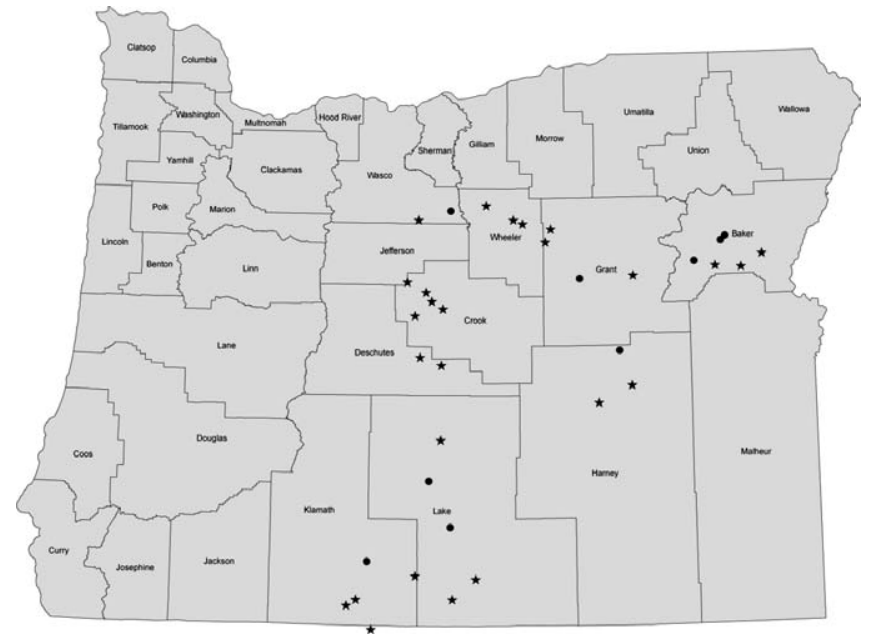

Figure 2. Location of areas where western juniper trees were sampled and potential abortifacient risks at those locations. Samples were collected from 10 trees per location at 35 different locations. $A \star$ denotes locations that pose a medium abortifacient risk; $\bullet$ denotes locations that pose a high abortifacient risk.

Oregon (Fig. 1). The sum of these four labdane acids is represented as the total. Berries had a higher concentration of ICA, IMB, DHAA, and total labdane acids than needles or bark, but the bark was highest in AA.

Samples of needles, bark, and berries were collected from 35 different locations (10 trees per location) across the state of Oregon and analyzed for labdane acid concentrations. Due to the fact that not all trees have berries, nor do the trees with berries have an equal number of berries, we only used the data from the needles and bark for the risk assessment. An average of the total labdane acid concentration of the bark and needles for each location was used to generate an estimation of the potential abortion risk of the western juniper trees at each location (Fig. 2). Any location with an average total labdane acid concentration of $0.5 \%$ or greater was considered a risk to cause abortions, and any location with an average labdane acid concentration greater than $1 \%$ was considered a high risk. Based on our results, there was a moderate abortifacient risk for the western juniper trees at 26 of the 35 locations sampled in this study, with a higher risk at the other nine locations (Fig. 2).

The western juniper trees that were evaluated in this study, at each location, should be considered a risk to cause abortions in late-term pregnant cattle. A statistical comparison of the different locations found very little difference from location to location due to the large variation from tree to tree at a given location (data not shown). For example, at location 8 , six of the 10 trees sampled had a total labdane acid concentration less than $0.5 \%$ (Table 1). Three of the trees sampled had a total labdane acid concentration of $0.5-1.0 \%$. This suggests that the majority of the trees at this location would pose a low to moderate risk. However, one of the trees at this location had a total labdane acid concentration greater than $8 \%$. This specific tree would pose an extremely high risk 
Table 1. An example of the high intralocation variability in labdane acid concentrations in bark between trees at one site in Oregon in August 2011. Concentrations of ICA, AA, or total above $0.5 \%$ indicate a medium risk if browsed by pregnant cattle. Especially note tree 1

\begin{tabular}{|c|c|c|c|c|c|}
\hline Tree & \% ICA & \% IMB & \% DHAA & $\%$ AA & \% Total \\
\hline 5 & 0.01 & 0.08 & 0.05 & 0.11 & 0.2 \\
\hline 9 & 0.01 & 0.05 & 0.05 & 0.16 & 0.3 \\
\hline 4 & 0.14 & 0.05 & 0.02 & 0.08 & 0.3 \\
\hline 8 & 0.01 & 0.03 & 0.02 & 0.29 & 0.4 \\
\hline 3 & 0.02 & 0.07 & 0.04 & 0.23 & 0.4 \\
\hline 2 & 0.07 & 0.12 & 0.08 & 0.12 & 0.5 \\
\hline 7 & 0.02 & 0.11 & 0.15 & 0.26 & 1.0 \\
\hline 10 & 0.01 & 0.37 & 0.08 & 0.19 & 8.4 \\
\hline 6 & 0.06 & 0.27 & 0.07 & 0.64 & 1.2 \\
\hline 1 & 7.91 & 0.16 & 0.06 & 0.24 & 2.5 \\
\hline Avg. & 0.83 & 0.13 & 0.06 & 0.23 & 0.16 \\
\hline SD & 2.49 & 0.11 & 0.04 & & 0.6 \\
\hline
\end{tabular}

Note: Data are presented as a percentage of dry weight plant material.

ICA indicates isocupressic acid; IMB, imbricatoloic acid; DHAA, dihydroagathic acid; AA, agathic acid; Total, sum of the four individual labdane acids; Avg., the average for the location; SD, the standard deviation for the location.

to cause abortions in cattle. Perhaps this high variation is one of the reasons that western juniper trees do not cause a large number of abortions. The likelihood of many cows browsing on a single high-risk tree is probably low.

Samples were collected from four of the same locations at two different time points, January 2011 and August 2011. Labdane acid profiles were compared from the four locations at the two collection times to determine if there is seasonal variation in the labdane acid content in western juniper trees (Figs. 3A and 3B). The results of the comparisons suggest that there are no changes in the concentration of the four labdane acids or their total over time (Fig. 3A). Similar results were observed at all four locations (Fig. 3B). These preliminary results suggest that there are no seasonal changes in the labdane acid content of western juniper trees. However, a more extensive analysis with samples collected multiple times throughout the year and over multiple years is needed to verify this preliminary finding. Additionally, in future studies, samples will be collected from the same tree each time in order to more accurately determine variability in individual trees over time.
Finally, we compared the labdane acid content of western juniper trees that have berries vs. trees without berries (Fig. 4). Berries have a high concentration of labdane acids and might affect the production or distribution of labdane acid such that the bark from trees with berries might have a lower concentration than trees without berries. Out of the 350 trees analyzed, 168 trees had berries and 182 trees did not have any berries. There was no difference in the concentration of any of the labdane acids between trees with and without berries, suggesting the presence of berries on the trees does not affect the production or distribution of labdane acids. Although there is no difference in abortion risk between trees with and without berries based solely on the concentrations of labdane acids, there are many other factors that might influence browsing on trees by cattle, and thereby alter abortion risk.

\section{Management Recommendations}

Controlled grazing studies have not been performed to specifically determine the factors that influence consumption of western juniper trees by cattle. However, after conversations we had with several ranchers who have experienced 

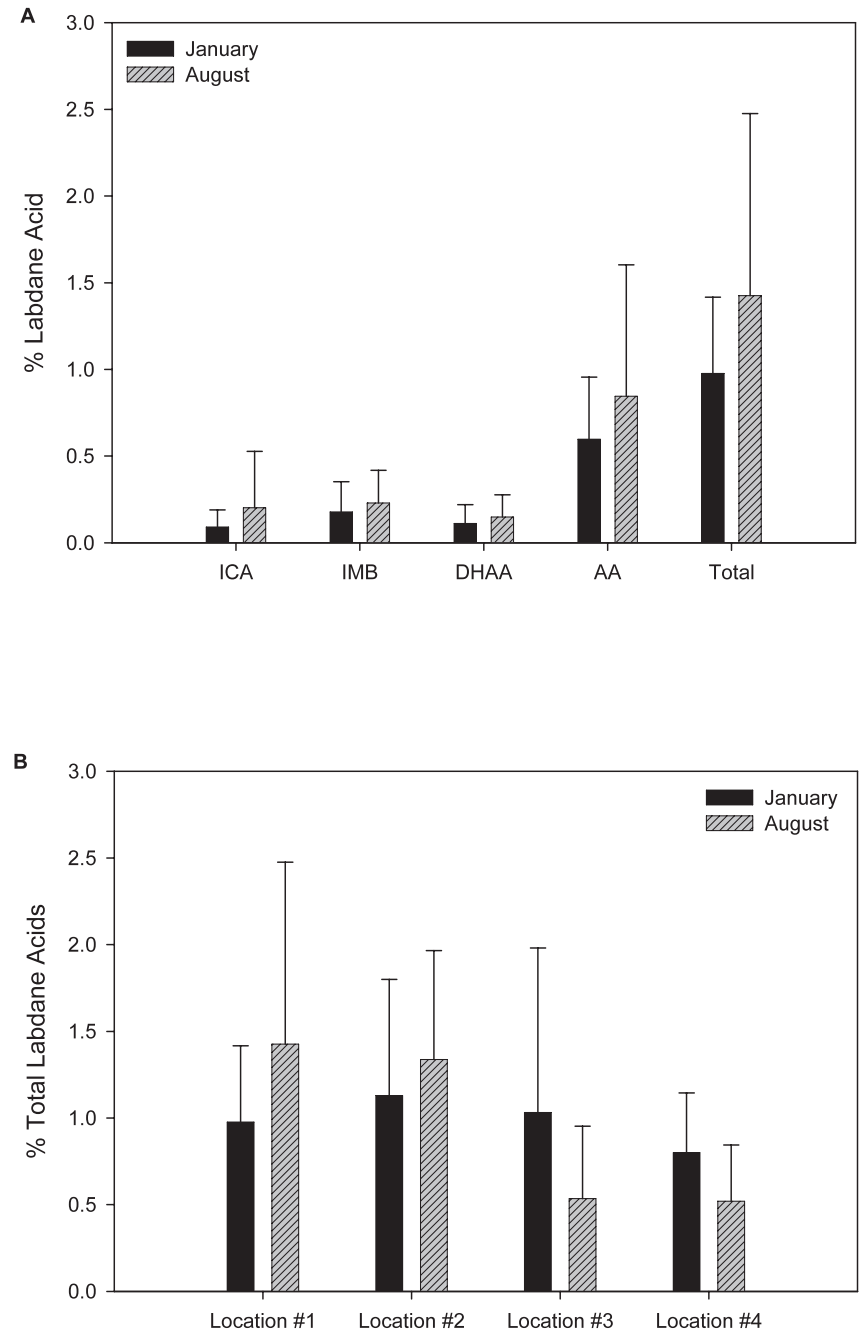

Figure 3. Comparison of labdane acid concentrations over time. Samples of bark from western juniper trees were collected at four different locations in Baker County, Oregon, in January 2011 and August 2011. A, A comparison of the labdane acids isocupressic acid (ICA), imbricatoloic acid (IMB), dihydroagathic acid (DHAA), agathic acid (AA), and their sum (TOTAL) at location 1. B, A comparison of the total labdane acid concentrations at all four locations. Data represent the mean \pm SD from 8-10 trees per location.

problems, it appears that juniper-induced abortions are very similar to pine needle-induced abortions (personal communications with ranchers). Consequently, the following recommendations are based upon both studies with ponderosa pine needles and our conversations with ranchers regarding western juniper-induced abortions.

Cattle appear to eat more juniper bark and needles from recently downed trees, either from trees found in slash piles or from debris after strong wind storms. Increased snow depth and lower daily temperatures can result in increased consumption. ${ }^{10,11}$ Additionally, cattle in low body condition may consume more juniper than cows in adequate body condition. $^{10}$

There are no known methods to prevent juniper-induced abortions; however, some basic recommendations may mini-

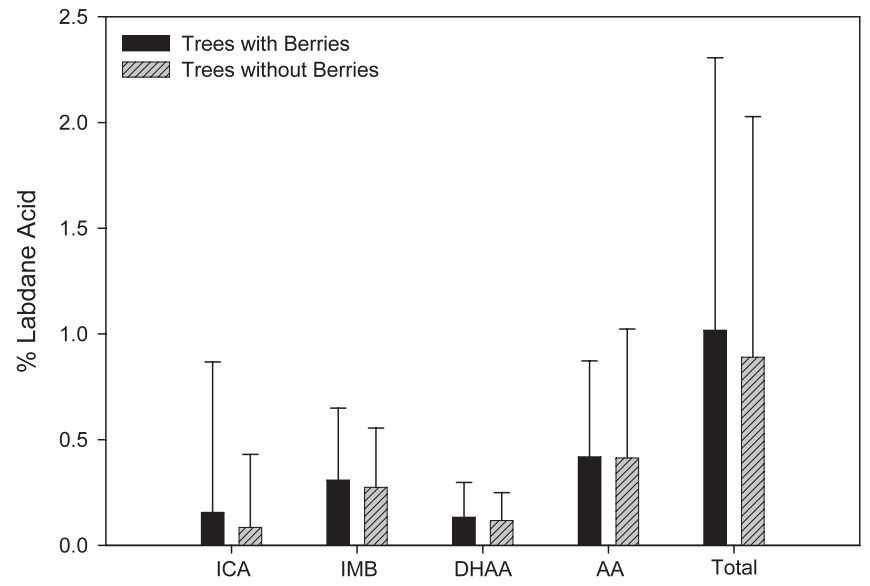

Figure 4. Comparison of the labdane acid concentrations in bark from western juniper trees with and without berries. The labdane acids analyzed were isocupressic acid (ICA), imbricatoloic acid (IMB), dihydroagathic acid (DHAA), agathic acid (AA), and their sum (TOTAL). Data represent the mean \pm SD from 10 trees per location at 35 different locations, comprising 168 trees with berries and 182 trees without berries.

mize the potential impact. First, deny pregnant cattle access to juniper trees during the third trimester of pregnancy, as this is when they are most susceptible. Second, provide adequate feed and shelter, as this will help to minimize juniper consumption. Third, maintain pregnant cattle in good body condition, which will also help to reduce juniper consumption. Fourth, if significant problems continue, change the calving schedules to late spring or fall to minimize the chance of experiencing extreme weather conditions that drive cattle into trees for shelter and can cause increased juniper consumption. Finally, if abortions do occur, it is advisable to seek veterinary care for associated postpartum complications such as retained placenta and endometritis. Also, late-term calves might survive, but they typically need extra care as they are usually weak and might not receive adequate colostrum or suckle normally.

\section{Conclusions}

Previous research has shown that western juniper trees can cause late-term abortions in cattle, similar to ponderosa pine trees. Initial analyses indicated that western juniper trees contain the same abortifacient compounds as ponderosa pine trees. Results presented in our study from over 400 trees from over 35 locations across the state of Oregon suggest western juniper trees in all areas present an abortion risk in pregnant cattle. The abortifacient compounds are found in bark, needles, and berries, with bark posing the most significant risk. There is substantial tree-to-tree variation, with some trees having extremely high concentrations of the abortifacient compounds and posing an extreme risk to cause abortions in cattle. Consequently, cattle producers who winter cattle in pastures with western juniper trees should take similar precautions to prevent late-term abortions as they would with ponderosa pine trees. 


\section{Acknowledgments}

The authors thank Kendra Dewey, Scott Larsen, and Clint Stonecipher for their expert technical support. The authors also wish to thank Tim Deboodt and Chanda Engel, Oregon State University extension agents, for their help and support in collecting western juniper samples as well as their expert review of the manuscript.

\section{References}

1. Panter, K. E., L. F. James, R. J. Molyneux, R. E. Short, and D. V. Sisson. 1990. Premature bovine parturition induced by ponderosa pine: effects of pine needles, bark and branch tips. Cornell Veterinarian 80:329-338.

2. Gardner, D. R., R. J. Molyneux, L. F. James, K. E. Panter, and B. L. Stegelmeier. 1994. Ponderosa pine needle-induced abortion in beef cattle: identification of isocupressic acid as the principal active compound. Journal of Agricultural and Food Chemistry 42:756-761.

3. Gardner, D. R., K. E. Panter, and L. F. James. 1999. Pine needle abortion in cattle: metabolism of isocupressic acid. Journal of Agricultural and Food Chemistry 47:2891-2897.

4. Lin, S. J., R. E. Short, S. P. Ford, E. E. Grings, and J. P. RosAzzA. 1998. In vitro biotransformations of isocupressic acid by cow rumen preparations: formation of agathic and dihydroagathic acids. Journal of Natural Products 61:51-56.

5. Panter, K. E., D. R. Gardner, S. T. Lee, J. A. Pfister, M. H. Ralphs, B. L. Stegelmeier, and L. F. James. 2007. Important poisonous plants of the United States. In: R. C. Gupta [ED.]. Veterinary toxicology: basic and clinical principles. New York, NY, USA: Academic Press. p. 825-872.

6. Gardner, D. R., K. E. Panter, and B. L. Stegelmeier. 2010. Implication of agathic acid from Utah juniper bark as an abortifacient compound in cattle. Journal of Applied Toxicology 30:115-119.

7. Welch, K. D., D. R. Gardner, K. E. Panter, B. L. Stegelmeier, C. Parsons, J. A. Pfister, and D. Cook. 2011. Western juniper-induced abortions in beef cattle. International Journal of Poisonous Plants 1:72-79.

8. Cook, D., D. R. Gardner, J. A. Pfister, K. E. Panter, B. L. Stegelmeier, S. T. Lee, K. D. Welch, B. T. Green, AND T. Z. Davis. 2010. Differences in ponderosa pine isocupressic acid concentrations across space and time. Rangelands 32(2):14-17.

9. Gardner, D. R., And L. F. James. 1999. Pine needle abortion in cattle: analysis of isocupressic acid in North American gymnosperms. Phytochemical Analysis 10:132-136.

10. Pfister, J. A., K. E. Panter, D. R. Gardner, D. Cook, and K. D. Welch. 2008. Effect of body condition on consumption of pine needles (Pinus ponderosa) by beef cows. Journal of Animal Science 86:3608-3616.

11. Pfister, J. A., and D. C. Adams. 1993. Factors influencing pine needle consumption by grazing cattle during winter. Journal of Range Management 46:394-398.

Authors are Research Toxicologist, kevin.welch@ars.usda.gov (Welch), Research Plant Physiologist (Cook), Research Chemist (Gardner), Research Rangeland Management Specialist (Pfister), and Supervisory Research Animal Scientist (Panter), USDAARS Poisonous Plant Research Laboratory, Logan, UT 84341, USA; and Regional Administrator South East Region (Region 2), Oregon State University, Baker County Extension Service, Baker City, OR 97814, USA (Parsons). 